\title{
Psychosocial Response to Uncertain Newborn Screening Results for Cystic Fibrosis
}

\section{Hayeems, Robin Z.}

2017-05

Hayeems , R Z , Miller , F A, Barg , C J , Bombard , Y , Carroll , J C , Tam , K, Kerr , E , Chakraborty , P , Potter , B K, Patton , S , Bytautas , J , Taylor , L , Davies , C , Milburn , J , Price , A , Gonska , T , Keenan , K, Ratjen , F \& Guttmann , A 2017 , ' Psychosocial Response to Uncertain Newborn Screening Results for Cystic Fibrosis ' , The Journal of Pediatrics , vol. 184 , pp. 165-171 . https://doi.org/10.1016/j.jpeds.2017.01.049

http://hdl.handle.net/10138/236977

https://doi.org/10.1016/j.jpeds.2017.01.049

unspecified

publishedVersion

Downloaded from Helda, University of Helsinki institutional repository.

This is an electronic reprint of the original article.

This reprint may differ from the original in pagination and typographic detail.

Please cite the original version. 


\title{
Psychosocial Response to Uncertain Newborn Screening Results for Cystic Fibrosis
}

\author{
Robin Z. Hayeems, ScM, PhD',2, Fiona A. Miller, PhD², Carolyn J. Barg, MSc², Yvonne Bombard, PhD ${ }^{2,3}$, June C. Carroll, MD", \\ Karen Tam, ScM ${ }^{5}$, Elizabeth Kerr, PhD ${ }^{6,7}$, Pranesh Chakraborty, $\mathrm{MD}^{8,9}$, Beth K. Potter, PhD ${ }^{10}$, Sarah Patton, $\mathrm{MA}^{2}$, \\ Jessica P. Bytautas, MSc ${ }^{2,11}$, Louise Taylor, NP ${ }^{12}$, Christine Davies, MSc $^{8}$, Jennifer Milburn, MHA $^{8}$, April Price, MD $^{13}$, \\ Tanja Gonska, MD ${ }^{14,15}$, Katherine Keenan, BSc ${ }^{12}$, Felix Ratjen, MD, PhD ${ }^{7,16}$, and Astrid Guttmann, MDCM, MSc ${ }^{1,27,12,17}$
}

Objective To explore the psychosocial implications of diagnostic uncertainty that result from inconclusive results generated by newborn bloodspot screening (NBS) for cystic fibrosis (CF).

Study design Using a mixed methods prospective cohort study of children who received NBS for CF, we compared psychosocial outcomes of parents whose children who received persistently inconclusive results with those whose children received true positive or screen-negative results.

Results Mothers of infants who received inconclusive results $(n=17)$, diagnoses of CF $(n=15)$, and screennegative results $(n=411)$ were surveyed; 23 parent interviews were completed. Compared with mothers of infants with true positive/screen-negative results, mothers of infants with inconclusive results reported greater perceived uncertainty $(P<.006)$ but no differences in anxiety or vulnerability $(P>.05)$. Qualitatively, parents valued being connected to experts but struggled with the meaning of an uncertain diagnosis, worried about their infant's healthrelated vulnerability, and had mixed views about surveillance.

Conclusion Inconclusive CF NBS results were not associated with anxiety or vulnerability but led to healthrelated uncertainty and qualitative concerns. Findings should be considered alongside efforts to optimize protocols for CF screening and surveillance. Educational and psychosocial supports are warranted for these families. ( $J$ Pediatr 2017; 184:165-71).

lthough the US Centers for Disease Control hails newborn screening (NBS) as one of the 10 great public health achievements of the last decade, ${ }^{1,2}$ increasingly sensitive NBS technology leads to the detection of a wider variety of test results (ie, false positive and inconclusive results) with complex effects, increasing the need for research to ensure the public health benefits of screening are maintained. ${ }^{3-6}$ We focus herein on the specific challenge of inconclusive results after diagnostic follow-up testing. For families of infants with such results, there is no clarity on whether a disease state exists and whether/how to manage it; uncertainty for parents and health care providers can persist for months or even years. ${ }^{7-21}$ As NBS panels continue to expand, evidence to identify the scope of parent-reported outcomes in the context of diagnostic uncertainty is timely. ${ }^{6}$

NBS for cystic fibrosis (CF) exemplifies the challenge of inconclusive results. ${ }^{9-15}$ Although diagnostic uncertainty is not a new phenomenon for individuals with symptoms of $\mathrm{CF},{ }^{10}$ NBS- related uncertainty is more complicated because most newborns are asymptomatic. Moreover, inconclusive CF diagnoses are quite frequent; in the first 6 years of NBS for CF in Ontario, Canada (population 13 million), 150 infants were identified with CF, whereas 68 received inconclusive results. ${ }^{12}$ Ooi et $\mathrm{al}^{16}$ recently reported 3 -year clinical outcomes of 82 children with inconclusive results and 80 children with CF; CF ultimately was diagnosed in 9 of 82 (11\%). Despite emerging evidence, practice varies with respect to CF screening algorithms, how to refer to this situation (eg, "CFTR-related metabolic syndrome," "CF screen positive, inconclusive diagnosis"), and optimal clinical surveillance. ${ }^{12-19}$

Given this context, the psychosocial impact of this experience warrants attention. The small number of related studies has yielded equivocal results. An

\footnotetext{
CF Cystic fibrosis

CFTR Cystic fibrosis transmembrane regulator

IRT Immunoreactive trypsinogen

NBS Newborn screening

RR Response rate
}

From the ${ }^{1}$ Child Health Evaluative Sciences, The Hospital for Sick Children Research Institute, Toronto, Canada; ${ }^{2}$ Institute of Health Policy, Management and Evaluation University of Toronto, Toronto, Canada; ${ }^{3} \mathrm{Li} \mathrm{Ka}$ Shing Knowledge Institute of St. Michael's Hospital, Toronto, Canada; ${ }^{4}$ Department of Family and Community Medicine, Mount Sinai Hospital, Sinai Health System University of Toronto, Toronto, Canada; ${ }^{5}$ Division of University of Toronto, Toronto, Canada; ${ }^{5}$ Division Pediatrics; ${ }^{6}$ Department of Psychology, The Hospital for Sick Children, Toronto, Canada; ${ }^{7}$ Department of Pediatrics, Faculty of Medicine, University of Toronto, Toronto, Canada; ${ }^{8}$ Newborn Screening Ontario, Children's Hospital of Eastern Ontario, Ottawa, Canada;

${ }^{9}$ Department of Pediatrics; ${ }^{10}$ School of Epidemiology,
Pentital of

Public Health \& Preventive Medicine, Faculty of Medicine, University of Ottawa, Ottawa, Canada; ${ }^{11}$ Department of

Public Health, University of Helsinki, Helsinki, Finland

${ }^{12}$ Department of Pediatrics, The Hospital for Sick

Children, Toronto, Canada; ${ }^{13}$ Department of Pediatric

Respirology, Children's Hospital of Western Ontario,

London, Canada; ${ }^{14}$ Division of Gastroenterology,

Department of Pediatrics The Hospital for Sick Children,

Toronto, Canada; ${ }^{15}$ Physiology and Experimental

Medicine, The Hospital for Sick Children Research

Institute, Toronto, Canada; ${ }^{16}$ Division of Respiratory

Medicine, Department of Pediatrics, The Hospital for Sick

Children, Toronto, Canada; and ${ }^{17}$ Health System Planning

\& Evaluation Research Program, Institute for Clinical

Evaluative Sciences, Toronto, Canada

Supported by a Canadian Institutes of Health Research operating grant (106505). The authors declare no conflicts of interest.

0022-3476/\$ - see front matter. @ 2017 Elsevier Inc. All rights reserved.

http://dx.doi.org10.1016/.jpeds.2017.01.049 
ethnography of the families of 24 infants with uncertain metabolic disease results suggests that families assume the role of "patients-in-waiting" ${ }^{20}$; parents perceive their children to be neither healthy nor sick for protracted periods of time, potentially influencing the identity parents attribute to their child. Although a CF-related, survey-based study did not detect clinical levels of anxiety among parents of children with uncertain CF diagnoses $(P>.05)$, when asked whether their child's health status caused them any emotional disturbances, significantly more parents of children with an uncertain diagnosis endorsed this concern than parents of healthy children $(P=.0003){ }^{21}$ In a qualitative interview study with 10 parents of 5 infants with inconclusive CF NBS results, Tluczek et $\mathrm{al}^{22}$ identified ongoing worry and feelings of isolation from the CF community; however, this negative affect became less pronounced over time..$^{22}$

Although qualitative and quantitative indicators of subtle distress have been reported, constructs specific to the experience of uncertainty in NBS have not been explored with validated psychometric tools. Perception of child vulnerability, for example, has been reported as a potential indicator of distress related to infant screening ${ }^{23-25}$ but has not yet been applied to inconclusive NBS diagnoses. Unsurprisingly, the construct of uncertainty also has been identified as central to the experience of receiving inconclusive NBS CF results ${ }^{22}$ but has not been explored with validated tools. We report on parental psychosocial impact and lived experiences of diagnostic uncertainty in collaboration with the International CF Consortium's efforts to generate prospective clinical outcome data to inform screening and follow-up protocols for these patients. ${ }^{16}$

\section{Methods}

In Ontario, CF NBS involves a 2-step process of measuring immunoreactive trypsinogen (IRT) followed by screening the cystic fibrosis transmembrane regulator (CFTR) gene for 39 mutations. ${ }^{16}$ Confirmatory sweat chloride testing is then performed on screen-positive infants who are classified subsequently as true positive (ie, $2 \mathrm{CF}$ causing mutations $\mathrm{OR}$ sweat chloride $\geq 60 \mathrm{mmol} / \mathrm{L}$ ), false positive (ie, $1 \mathrm{CF}$ causing mutation OR IRT $>99.9$ th percentile PLUS sweat chloride concentration $<30 \mathrm{mmol} / \mathrm{L}$ ), or inconclusive (ie, 1 CFTR mutation OR IRT $>99.9$ th percentile PLUS sweat chloride 30-59 mmol/L OR sweat chloride concentration $<30 \mathrm{mmol} /$ $\mathrm{L}+>1$ CFTR mutations of uncertain significance). Inconclusive cases are offered ongoing clinical and/or research follow-up. This includes optional monitoring and assessment every 6 months following confirmatory testing until 2 years of age and then annually. Sweat testing, microbiology testing, and clinical assessment of respiratory and gastrointestinal symptoms are included in each assessment. Parents choose to opt into/out of any of these assessments and can opt into/out of including their child's assessment data in the research database.

\section{Sample}

For the component of the study reported herein, the full population of mothers of infants with true positive and inconclusive results seen at The Hospital for Sick Children in Toronto and a screen negative control sample were invited to participate during an 18-month period, via a modified Dillman design. ${ }^{26,27}$ Because of the small number of inconclusive cases, we broadened the inclusion age, recruiting mothers retrospectively whose infants remained inconclusive with respect to diagnosis and were between the ages of 4 and 48 months or were seen at London Health Sciences Centre, a second regional NBS center in London, Ontario. The control group included a random sample of mothers of infants who screened negative for all conditions, identified through Newborn Screening Ontario. Most questionnaire data were collected from mothers of screen-positive and -negative infants when they were 4-6 weeks of age. For mothers of infants identified retrospectively, data were collected when infants were 6-48 months of age. Mothers of infants facing extenuating perinatal stressors (eg, infants deceased, in clinical distress, premature, multiples), those undergoing adoption proceedings, or with significant language barriers were excluded, as well as those cases requiring additional testing for technical reasons. The Research Ethics Boards at The Hospital for Sick Children, The Children's Hospital of Eastern Ontario, Western University, and The University of Toronto approved the study.

\section{Data Collection}

We collected psychosocial data through a cross-sectional, selfadministered questionnaire and semistructured open-ended interviews with mothers. We report quantitative psychosocial data from mothers of infants with inconclusive, true positive, and screen-negative results and qualitative interview data from parents of infants with inconclusive diagnoses following confirmatory testing.

\section{Survey of Mothers}

The survey package included a team-developed, selfadministered questionnaire gauging knowledge of CF, understanding of screening result, attitudes towards NBS, psychosocial measures, and demographic questions and relevant study information, consent, forms, and a small financial incentive (a $\$ 2$ coffee shop coupon). The questionnaire was pretested with new parents recruited from the Greater Toronto Area $(\mathrm{N}=15)$ through an online mothers' group (to reflect mothers of "healthy" children) and the CF community (to reflect mothers of children with $\mathrm{CF}$ ).

The team-developed questionnaire was adapted from existing validated instruments used in infant/NBS research. ${ }^{21-25,27-29}$ The core questionnaire was consistent across groups; content specific to the screen-positive experience was excluded from the version distributed to the screen-negative control group. We present overall scores on 3 well-established and validated psychosocial response measures: ${ }^{27}(1)$ the state subscale of the State Trait Anxiety Inventor $y^{28}$ as a measure of parental anxiety, (2) a modified version of the Parental Perceptions of Uncertainty in Illness Scale ${ }^{29}$ as a measure of perceived uncertainty 
related to childhood illness, and (3) the Child Vulnerability Scale $^{24}$ as a measure of maternal perception of infant vulnerability.

Questionnaire data were manually entered into IBM SPSS Statistics, version 18 (IBM Corp, Armonk, New York). Double data entry was performed for the uncertain and true positive samples. Two cases were removed from the quantitative analysis because their inconclusive results were verified to be true negative at the time of survey completion (ie, by 6 months of age; Figure available at www.jpeds.com). We quantified the overall pattern of responses using proportions for discrete variables and medians with IQRs for continuous variables. We performed nonparametric tests of significance given non-normal distributions of the data.

\section{Interviews with Parents}

Interview respondents were recruited from those who had inconclusive results, had completed a questionnaire, and indicated willingness to participate in an interview, or expressed a preference to complete an interview rather than a questionnaire. Because qualitative interviews were retrospective in nature, the 2 "resolved" cases that were removed from the quantitative analysis remained in the qualitative sample (Figure). When both parents were present at the time of the interview, both were invited to participate. We conducted telephone interviews when face-to-face interviews were not feasible. One member of the study team conducted all interviews.

The interview guide queried parents' experiences receiving the screen-positive notification, their preparation for and experience during the sweat test appointment, their understanding of the screening and test results, and their lived experience thereafter as related to parenting and medical followup. We captured parents' experience over time in 2 ways. First, all interviews were retrospective in nature, enabling parents to reflect back on their experience. Second, parents were invited to participate in a second interview 1 year following their first interview. Interview data were taped, transcribed, and coded by the project team. We used interpretive description, a low inference analytic strategy that draws on the tenets of naturalistic inquiry and emphasizes a close engagement with the respondent's own representation of events, to analyze transcript data. ${ }^{30}$ Using a thematic approach, we applied and modified pre-existing codes (from the interview guide) as sensitizing concepts and allowed new themes to emerge from the data. Codes were generated by the authors and transcripts were coded independently by an additional author. Through an iterative process, codes were refined and inconsistencies were resolved by discussion.

\section{Results}

Eligible mothers of 39 infants who received inconclusive diagnoses were invited to participate; 19 completed the survey (response rate [RR] 48.7\%) and 2 were excluded from the survey analysis because their inconclusive results were verified to be true negative at the time of survey completion. Fifteen surveys were completed by mothers of true-positive infants
(RR 62.5\%), and 410 surveys were completed by mothers of screen-negative infants (RR 47.2\%). ${ }^{27}$ Mothers of infants with inconclusive diagnoses lived in less urban locations and were less well educated than both comparison groups $(P<.05)$ and had greater household income than the screen-negative control group $(P=.01)$ (Table I).

\section{Psychosocial Results}

Anxiety and vulnerability scores among mothers of infants with inconclusive diagnoses were not different from mothers of true positive infants or mothers of screen-negative controls. Mothers of infants with inconclusive diagnoses reported greater perceived uncertainty scores than mothers of true positive infants $(P=.002)$ and screen-negative infants $(P<.001)$ (Table II). Itemized Parental Perceptions of Uncertainty in Illness Scale responses indicate that compared with mothers of true positive and screen-negative infants, more mothers of infants with inconclusive results were unsure about whether their infant had a health condition $(P=.002)$. Compared with mothers of screen-negative infants, mothers of infants with inconclusive results had "unanswered questions about their baby's health" $(P=.001)$ and heard "many meanings" from doctors about their baby's health $(P<.001)$ (Table III).

\section{Qualitative Interview Sample}

Parents of 18 children were interviewed (parents of 13 children were interviewed once, and parents of 5 children were interviewed twice, with the second interview 1 year following the first interview). For 2 of these children, inconclusive results were resolved as true negatives. For 16 children, mothers were interviewed; for 2 children, both mother and father were interviewed ( $\mathrm{n}=20$ parents). Children ranged from 4 months to 4 years old.

\section{Qualitative Findings}

Parents of infants with inconclusive results experienced relief that their child did not have "full-blown" CF and appreciated the value the knowledge might have for the child or other family members in the future. They struggled, however, to make sense of what was perceived as an uncomfortable diagnostic category. The experience of uncertainty involved 3 additional dimensions: unsettled meaning, heightened sense of medical vulnerability, and mixed feelings about surveillance (Table IV).

Unsettled Meaning. Parents described being unsettled about an inconclusive diagnosis, particularly in the face of a child who "looks perfect." They reported being uncertain — and therefore unsettled-about the nature of the health complications that their child might experience, as well as the timing of potential CF-related manifestations. Parents reported receiving different messages from providers about what inconclusive results meant; some providers characterized inconclusive results as a potential form of disease (eg, "atypical CF") where symptoms could emerge anytime, "in six months or ten years or fifty years. .." (participant ID 106), whereas others avoided using a disease label. 


\begin{tabular}{|c|c|c|c|c|c|}
\hline \multirow[b]{2}{*}{ Characteristics } & \multirow{2}{*}{$\begin{array}{c}\begin{array}{c}\text { Inconclusive } \\
\mathrm{n}=17\end{array} \\
\mathrm{n}(\%)\end{array}$} & \multicolumn{2}{|c|}{$\begin{array}{l}\text { True positive } \\
\quad n=15\end{array}$} & \multicolumn{2}{|c|}{$\begin{array}{c}\text { Screen negative } \\
\quad n=410\end{array}$} \\
\hline & & n (\%) & $P$ value $^{\dagger}$ (vs uncertain) & n (\%) & $P$ value $^{\dagger}$ (vs uncertain) \\
\hline \multicolumn{6}{|l|}{ Age, y } \\
\hline$\leq 25$ & $0(0.0)$ & $1(6.7)$ & .075 & $27(6.7)$ & .127 \\
\hline $26-30$ & $2(11.8)$ & $2(13.3)$ & & $110(27.1)$ & \\
\hline $31-35$ & $6(35.3)$ & $10(66.7)$ & & $160(39.4)$ & \\
\hline $36+$ & $9(52.9)$ & 2 (13.3) & & $109(26.8)$ & \\
\hline \multicolumn{6}{|l|}{ City size } \\
\hline $100000+$ & 7 (41.2) & $12(80.0)$ & .036 & $330(80.5)$ & .001 \\
\hline$<100000$ & $10(58.8)$ & $3(20.0)$ & & $80(19.5)$ & \\
\hline \multicolumn{6}{|l|}{ First child } \\
\hline Yes & $10(58.8)$ & $9(60.0)$ & 1.000 & $127(40.3)$ & .139 \\
\hline No & 7 (41.2) & $6(40.0)$ & & $188(59.7)$ & \\
\hline \multicolumn{6}{|l|}{ Marital status } \\
\hline Married or common law & $16(94.1)$ & $14(86.7)$ & 1.000 & $380(92.7)$ & 1.000 \\
\hline Single & $1(5.9)$ & $1(6.7)$ & & $30(7.3)$ & \\
\hline \multicolumn{6}{|c|}{ Education, highest level completed } \\
\hline High school or less & $0(0.0)$ & $1(7.1)$ & .043 & $57(14.0)$ & .047 \\
\hline College or CEGEP & $11(64.7)$ & $3(21.4)$ & & $107(26.2)$ & \\
\hline Undergraduate & $2(11.8)$ & $6(42.9)$ & & $112(27.5)$ & \\
\hline Graduate or professional & $4(23.5)$ & $4(28.6)$ & & $132(32.4)$ & \\
\hline \multicolumn{6}{|l|}{ Income } \\
\hline$<\$ 80000$ & $2(12.5)$ & $2(14.3)$ & 1.000 & $180(45.2)$ & .010 \\
\hline$\$ 80000+$ & $14(87.5)$ & $12(85.7)$ & & $218(54.8)$ & \\
\hline
\end{tabular}

CEGEP, collège d'enseignement général et professionnel.

${ }^{\star}$ Discrepancies in response totals due to missing data.

†Fisher exact test.

$P<.05$.

$P<.01$.

Heightened Sense of Medical Vulnerability. Diagnostic uncertainty led some parents to perceive their child as medically vulnerable, leading to active symptom seeking. Parents described, "licking their babies for saltiness (ID 147)"; they also affixed CF-related meaning to unusual but normal newborn behavior (eg, spitting up). Others sought symptoms less actively but emphasized feeling a heightened sense of awareness or sensitivity towards ultimately benign coughs and colds.

In some cases, health-related vulnerability had a cascade of effects: parents reported delayed infant bonding or altered parenting/decision-making styles. With time, however, most described growing confidence in their child's health and a much-decreased sense of medical vulnerability.
Mixed Feelings About Surveillance. Families faced decisions related to continuing assessment through the clinic. At the time of the qualitative interviews, all families (except the 2 for whom results resolved) remained engaged in this followup protocol. Participants expressed belief that being engaged in ongoing monitoring contributed to needed knowledge for themselves and for science and enabled access to medical experts that would not otherwise be available; however, many also viewed the process as emotionally draining for themselves and/ or their otherwise-healthy child. For some, gaining confidence in their child's health over time reduced the perceived burden of ongoing surveillance. Others were less favorable towards ongoing surveillance as their children got older and feared psychological vulnerability related to potential labeling effects.

Table II. Mothers' psychosocial response to newborn screening results

\begin{tabular}{|c|c|c|c|c|c|}
\hline \multirow{2}{*}{$\begin{array}{l}\text { Psychosocial response } \\
\text { measures }\end{array}$} & \multirow{2}{*}{$\frac{\text { Inconclusive }(\mathrm{n}=17)^{*}}{\text { Median (IQR) }}$} & \multicolumn{2}{|c|}{ True positive $(n=15)^{\dagger}$} & \multicolumn{2}{|c|}{ Screen negative $(n=410)^{\ddagger}$} \\
\hline & & Median (IQR) & $P$ value $^{\S}$ (vs inconclusive) & Median (IQR) & $P$ value $^{\S}$ (vs inconclusive) \\
\hline STAl" & $33.50(18.00)$ & $38.00(14.00)$ & .092 & $31.00(12.00)$ & .927 \\
\hline $\mathrm{CVS}^{\star *}$ & $7.00(8.00)$ & $7.50(8.25)$ & .681 & $5.00(7.00)$ & .082 \\
\hline PPUS $^{\dagger \dagger}$ & $12.00(5.00)$ & 8.00 (3.25) & .002 & $8.00(3.00)$ & $<.001$ \\
\hline
\end{tabular}

CVS, Child Vulnerability Scale; PPUS, Parental Perceptions of Uncertainty Scale; STAI, State Trait Anxiety Inventory.

${ }^{*}$ STAl and PPUS $\mathrm{n}=16$ due to missing data.

tPPUS and CVS $n=14$ due to missing data.

‡STAl, $n=379 ;$ CVS, $n=396 ;$ PPUS, $n=404$ due to missing data.

§Mann-Whitney $U$ test.

ISTAl: state subscale used; scores range from 20 to 80 ; mean (working women) is 34.79 ( $S D=9.22$ ); mean (14 weeks' postpartum women) $30.43 .^{28}$

${ }^{*} \mathrm{CVS}$ : scores range from 0 to 24 . In a clinical population, scores $\geq 10$ indicate elevated perceptions of vulnerability. ${ }^{24}$

††PPUS: scores range from 0 to 20 ; greater scores indicate greater perception of uncertainty. ${ }^{29}$ 
Table III. Parental perceptions of uncertainty (itemized responses to PPUS)

\begin{tabular}{|c|c|c|c|c|c|}
\hline \multirow[b]{2}{*}{ Questions } & \multirow{2}{*}{$\frac{\text { Inconclusive }(n=17)^{*}}{n(\%)}$} & \multicolumn{2}{|c|}{ True positive $(n=15)^{\dagger}$} & \multicolumn{2}{|c|}{ Screen negative $(n=410)^{\ddagger}$} \\
\hline & & $\mathbf{n}(\%)$ & $\begin{array}{c}P \text { value }^{\S} \text { (vs } \\
\text { inconclusive) }\end{array}$ & n (\%) & $\begin{array}{c}P \text { value }^{\S} \text { (vs } \\
\text { inconclusive) }\end{array}$ \\
\hline \multicolumn{6}{|c|}{ 1. I have no idea whether or not my baby has a health problem } \\
\hline Strongly agree/agree & $7(43.8)$ & 0 & .002 & $43(10.6)$ & .002 \\
\hline Undecided & $2(12.5)$ & 0 & & $53(13.1)$ & \\
\hline Strongly disagree/disagree & 7 (43.8) & $14(100.0)$ & & $308(76.2)$ & \\
\hline \multicolumn{6}{|c|}{ 2. I have a lot of questions without answers about my baby's health } \\
\hline Strongly agree/agree & 7 (41.2) & $1(6.7)$ & .083 & $42(10.4)$ & .001 \\
\hline Undecided & $2(11.8)$ & $2(13.3)$ & & $33(8.1)$ & \\
\hline Strongly disagree/disagree & $8(47.1)$ & $12(80.0)$ & & $330(81.5)$ & \\
\hline \multicolumn{6}{|c|}{ 3. Doctors say things about my baby that could have many meanings } \\
\hline Strongly agree/agree & $6(37.5)$ & $3(20.0)$ & .545 & $30(7.4)$ & $<.001$ \\
\hline Undecided & $3(18.8)$ & $2(13.3)$ & & $31(7.7)$ & \\
\hline Strongly disagree/disagree & 7 (43.8) & $10(66.7)$ & & $344(84.9)$ & \\
\hline \multicolumn{6}{|c|}{ 4. I know what my baby's chances are of getting sick } \\
\hline Strongly agree/agree & 7 (41.2) & $4(26.7)$ & .045 & $165(40.7)$ & .344 \\
\hline Undecided & $3(17.6)$ & $9(60.0)$ & & $129(31.9)$ & \\
\hline Strongly disagree/disagree & 7 (41.2) & $2(13.3)$ & & $111(27.4)$ & \\
\hline
\end{tabular}

*Items 1 and $3 n=16$ due to missing data.

†ltem $1 \mathrm{n}=14$ due to missing data.

fltem $1 \mathrm{n}=404$ and items 2, 3, and $4 \mathrm{n}=405$ due to missing data.

§Fisher exact test.

$P<.05$.

$P<.01$

\section{Table IV. Qualitative themes and illustrative quotes}

\section{Relief and value placed on knowledge unto itself, for most}

"I was relieved and I was interested in how it all worked so I wanted to know all the details. . . it's important, you know, it probably will have little effect on her life, so I'm not that concerned but we wanted to have all the information for her. .." (ID 292)

"I really thought about [her getting sick] all day and night for a month. . . . And you can't get that month back. [. . .] It's still taking a while to let that go. I feel like I missed out on just enjoying that month. [ . . .] the most upsetting part about this is I feel like I didn't do the same things that I would have done with her. .." (ID 055)

\section{Unsettled meaning}

“. . . it's one of those weird genes. . .he doesn't have classic CF but we can't say that he doesn't have CF at all; it was very wishy-washy which was unsettling. . . I walked away feeling confused. .." (ID 033)

"at least we knew it was not the classic form. . . they said. . .he may have some organ problems later in life that are associated, like, stomach or lung problems. . ." (ID 296)

"one doctor said, it looks like she has atypical cystic fibrosis and here's what you might expect in the future, like pneumonia, sinus infections. ... Another doctor said, I don't want you to use atypical cystic fibrosis in regards to your daughter. At this point she's a completely healthy child. . . she has the makings of someone who may have atypical symptoms in the future, but at this point, there's nothing wrong with her. .." (ID 190)

\section{Heightened sense of medical vulnerability}

"he's got this cough. . .it drives me insane, I hate it, they say CF carriers are a little bit more mucousy. . . and that it's a normal cough, nothing to be alarmed; but when he gets mucousy it's horrible,... you're constantly thinking like, OK, well, is the CF active now?" (ID 172)

"I stayed up every night from when she was born. I was sleeping in her room with my hand on her back to make sure that I could feel her breathing. . .. It was. . . probably until she was about 2 that I wasn't worried about it on a daily basis. . . and even now. . . she's treated differently. . . Even though she's not sick, she's got a diagnosis. . . We looked at going up to [small town] but we didn't because of the air quality_-I wasn't sure how that would affect her. . ." (ID 106)

"I think, as hard as it was when she was little, we were still grateful to know and we still are now, like it's, we don't think about it and worry about it often, at all anymore, so it's not, it's not a big issue for our family right now. ..." (ID 404)

\section{Mixed feelings about surveillance}

“. . . I would rather know than not know. . .because she's being monitored and we don't, I feel like we don't have to worry about it as much as we would if, you know, she was 15 and all of a sudden, like oh, well she's had all these years of not getting enough of vitamins or has fluid in her lungs, or whatever, mucus, so no, I'm very glad that we know about it, even though it kind of sucks." (ID 404)

"We mostly go just for the research aspect. . .And that way whatever they can find out about her to help other kids would be great. . .But I also get to know that her scans come back clear, her chest x-rays, her ultrasounds. And it gives a little bit peace of mind for myself. . . So I think I do it more for the reassurance for myself. .." (ID 168)

"Once I had a really strong sense that he was in the clear I did not want anybody else to have to go through that uncertainty. If there's anything I can do to contribute to them just knowing a little bit more then I want to do it." (ID 176)

". . . it's very draining as a parent. . . At our last visit the doctor said, 'well her stomach's a little distended, let's check her intestines.' And I'm like, this has to stop. At some point this, looking for every single thing, has to stop. If we're talking about severe respiratory infections, ok, then l'Il look at it. But, if her stomach's a little distended, maybe she ate a little more?" (ID 106)

"I'm pro research. ... but I don't want him to think something's wrong with him. . . Kids with classic CF or who are symptomatic need to see doctors. . . If he's a healthy boy, I'm not opposed to research. . . but at what cost? It was not an issue in his first 18 months but now he's becoming much, much, much more aware. You know, we came home from the hospital last month and he said, 'am I sick?' He said, 'I sick? I sick?" (ID 033) 


\section{Discussion}

We explored the experience of, and psychosocial response to, diagnostic uncertainty following CF NBS. Encouragingly, inconclusive results were not associated with measurable anxiety or vulnerability among mothers of infants who received these results; however, our data do signal various manifestations of health-related uncertainty and subtle distress. Qualitatively, parents reflected relief about the absence of frank disease but uncertainty about what an inconclusive diagnosis means, what to expect medically, and how to manage their child's needs in the face of this uncertainty. Despite these challenges, parents felt supported by and endorsed regular monitoring in the early days, valued the ongoing relationships with experts, and supported the goals of research. As parents gained confidence in their child's health over time, some came to question ongoing monitoring because of its potential negative impact on their child's identity, whereas others continued to feel supported by it. These findings extend those of other studies, ${ }^{20-22}$ which report subtle forms of emotional disturbance among parents of infants with inconclusive diagnoses.

Our findings contribute to ongoing debates about the implications of diagnostic uncertainty for NBS practices and policies related to generating inconclusive results and optimizing support for families who receive them. New evidence indicates that some of these infants ultimately have CF; some would argue that this evidence justifies their early identification and initiation of treatment, whereas others, like Massie and Clements, ${ }^{14}$ argue that, "missing these infants on NBS is an acceptable limitation of the program that is by nature a screening program." In addition, recent work suggests that the general public understands the concept of unclear screening diagnoses and views this outcome unfavorably. ${ }^{31}$ Although we did not detect a clear quantitative signal of psychosocial harm, a clear qualitative signal of distress suggests that continued expansion of NBS, in turn generating more complex-to-interpret results, may not be a harmless trend. Combined with related work, our findings underscore the importance of using patientreported outcomes that reflect on both the benefits and potential harms of inconclusive results in decisions related to suitable screening targets and optimal screening algorithms. ${ }^{31}$

Evidence on the family experience of receiving inconclusive results and pursuing surveillance also can inform the development of evidence-based postscreening care and surveillance protocols. Our findings suggest that NBS providers, primary care providers, and specialists implicated in short- and longer-term postscreening care (ie, notification, confirmatory testing, ongoing surveillance) may be called on to assess and attend to parents' psychosocial response to this consequence of screening. Because the newborn period is a time of critical parent-child bonding and identity shaping for both parents and their infants, ${ }^{20,32}$ equipping the postscreening care system with capacity to respond with clear messaging, evidencebased protocols, and educational/psychosocial support resources is warranted. Because our findings related to diagnostic uncertainty pertain to a less urban and less well-educated parent group, we infer that these particular demographic categories may be more vulnerable to subtle distress and require additional support. Finally, our findings add to the debate about whether and how prospective parents should be informed of this possible outcome in advance of NBS. Although many have emphasized the potential value of fulsome pre-NBS education, ${ }^{33}$ NBS typically is not accompanied by formal systems of pretest education and consent through which parents can be apprised of this possible outcome. ${ }^{33-35}$ This current structural reality places further pressure on optimizing both the screening algorithm as well as the postscreening care environment.

We acknowledge the limitations of this relatively small, primarily single-site sample, and variable age ranges and time of assessment since the diagnostic uncertainty was declared. The salience of the qualitative findings related to perceived vulnerability combined with the subtle quantitative trend towards increased vulnerability among those with inconclusive results highlights the possibility that this study was underpowered to detect meaningful differences on this dimension. Our study sample also may not be fully representative of the population of infants and families affected by diagnostic uncertainty. Nonetheless, this work adds to the knowledge base regarding the psychosocial impact of medical surveillance triggered by diagnostic uncertainty from CF NBS. It is novel in its mixed methods approach and contributes to our understanding of the complex nature of NBS-generated uncertainty. Further evaluation, and support for these families, is warranted.

We thank Dr Chee Y. Ooi, MBBS Dip Paeds FRACP PhD, University of New South Wales (UNSW) and Sydney Children's Hospital Randwick, Australia, for his central role in establishing the clinical cohort.

Submitted for publication Aug 18, 2016; last revision received Dec 15, 2016; accepted Jan 19, 2017

Reprint requests: Robin Z. Hayeems, ScM, PhD, Hospital for Sick Children Research Institute, 686 Bay St, 11.9710, Toronto, ON M5G 0A4, Canada. E-mail: robin.hayeems@ sickkids.ca

\section{References}

1. Bonham JR. Impact of new screening technologies: should we screen and does phenotype influence this decision? J Inherit Metab Dis 2014;36:6816

2. Centers for Disease Control and Prevention (CDC). Ten great public health achievements-United States, 2001-2010. MMWR Surveill Summ 2011;60:619-23.

3. Van Spronsen J. Mild hyperphenylalaninemia: to treat or not to treat. J Inherit Metab Dis 2011;34:651-66.

4. Potter BK, Little J, Chakraborty P, Kronick JB, Evans J, Sutherland SC, et al. Variability in the clinical management of fatty acid oxidation disorders: results of a survey of Canadian metabolic physicians. J Inherit Metab Dis 2012;35:115-23.

5. Miller FA, Begbie M, Giacomini M, Ahern C, Harvey EA. Re-defining disease? The nosologic implications of molecular genetic knowledge. Perspect Biol Med 2006;49:99-114.

6. Goldenberg AJ, Comeau AM, Grosse SD, Tanksley S, Prosser LA, Ojodu J, et al. Evaluating harms in the assessment of net benefit: a framework for newborn screening condition review. Matern Child Health J 2016;20:693-700. 
7. Fletcher JM. Diagnosis and management support for an expanded newborn screening programme. Ann Acad Med Singapore 2008;37:2732.

8. Wilcken B. Expanded newborn screening: reducing harm, assessing benefit. J Inherit Metab Dis 2010;33:S205-10.

9. Burke W, Tarini B, Press NA, Evans JP. Genetic screening. Epidemiol Rev 2011;33:148-64

10. Massie J, Gillam L. Uncertain diagnosis after newborn screening for cystic fibrosis: an ethics- based approach to a clinical dilemma. Pediatr Pulmonol 2014;49:1-7.

11. Farrell PM, Rosenstein BJ, White TB, Accurso FJ, Castellani C, Cutting GR, et al. Guidelines for diagnosis of cystic fibrosis in newborns through older adults: cystic fibrosis foundation consensus report. J Pediatr 2008;153:S4-14.

12. Newborn Screening Ontario. Newborn Screening Ontario Annual Report. https://www.newbornscreening.on.ca/en/about-us/annual-reports; 2013. Accessed February 21, 2017.

13. Borowitz D, Parad RB, Sharp JK, Sabadosa KA, Robinson KA, Rock MJ, et al. Cystic Fibrosis Foundation practice guidelines for the management of infants with cystic fibrosis transmembrane conductance regulatorrelated metabolic syndrome during the first two years of life and beyond. J Pediatr 2009;155:S106-16.

14. Massie J, Clements B, Australian Paediatric Respiratory Group. Diagnosis of cystic fibrosis after newborn screening: the Australasian experiencetwenty years and five million babies later: a consensus statement from the Australasian Paediatric Respiratory Group. Pediatr Pulmonol 2005;39:4406.

15. Levy H, Nugent M, Schneck K, Stachiw-Hietpas D, Laxova A, Lakser O, et al. Refining the continuum of CFTR-associated disorders in the era of newborn screening. Clin Genet 2016;89:539-49.

16. Ooi CY, Castellani C, Keenan K, Avolio J, Volpi S, Boland M, et al. Inconclusive diagnosis of cystic fibrosis after newborn screening. Pediatrics 2015; 135:e1377-85.

17. ECFS Neonatal Screening Working Group. May 2014 Report. https:// www.ecfs.eu/sites/default/files/general-content-files/working-groups/ NSWGReportMay2014.pdf. Accessed February 24, 2017.

18. Mayell S. Management of equivocal diagnosis, the European consensus project. Presentation, European Cystic Fibrosis Conference 2014, Gothenburg, Sweden, June 13, 2014.

19. Ren CL, Desai H, Platt M, Dixon M. Clinical outcomes in infants with cystic fibrosis transmembrane conductance regulator (CFTR) related metabolic syndrome. Pediatr Pulmonol 2011;46:1079-84.
20. Timmermans S, Buchbinder M. Patients-in-waiting: living between sickness and health in the genomics era. J Health Soc Behav 2010;51:40823.

21. Perobelli S, Zanolla L, Tamanini A, Rizzotti P, Maurice Assael B, Castellani C. Inconclusive cystic fibrosis neonatal screening results: long-term psychosocial effects on parents. Acta Paediatr 2009;98:1927-34.

22. Tluczek A, McKechnie A, Lynam P. Cystic fibrosis label does not fit: a model of uncertainty theory. Qual Health Res 2010;20:209-33.

23. Kokotos F. The vulnerable child syndrome. Pediatr Rev 2009;30:193-4.

24. Forsyth B, Horowitz SM, Leventhal JM, Burger J, Leaf PJ. The child vulnerability scale: an instrument to measure parental perceptions of child vulnerability. J Pediatr Psychol 1996;21:89-101.

25. Kerruish NJ, Campbell-Stokes PL, Gray A, Merriman TR, Robertson SP, Taylor BJ. Maternal psychological reaction to newborn genetic screening for type 1 diabetes. Pediatrics 2007;120:e324-35.

26. Dillman D, Smyth J, Christian L. Internet, mail, and mixed-mode surveys: the tailored design method. 3rd ed. Hoboken (NJ): John Wiley \& Sons, Inc.; 2009.

27. Hayeems RZ, Miller FA, Barg CJ, Bombard Y, Kerr E, Tam K, et al. Parent experience with false positive newborn screening results for cystic fibrosis. Pediatrics 2016;138:[Epub ahead of print].

28. Spielberger C, Gorsuch R, Lushene R, Vagg PR, Jacobs GA. State-trait anxiety inventory. Palo Atlo (CA): Consulting Psychologists Press, Inc; 1983.

29. Mishel MH. Parents' perception of uncertainty concerning their hospitalized child. Nurs Res 1983;32:324-30.

30. Thorne S, Kirkham SR, MacDonald-Emes J. Interpretive description: a noncategorical qualitative alternative for developing nursing knowledge. Res Nurs Health 1997;20:169-77.

31. Miller FA, Hayeems RZ, Bombard Y, Cressman C, Barg CJ, Carroll JC, et al. Public perceptions of the benefits and risks of newborn screening. Pediatrics 2015;136:e413-23.

32. Grob R. Is my sick child healthy? Is my healthy child sick? Changing parental experiences of cystic fibrosis in the age of expanded newborn screening. Soc Sci Med 2008;67:1056-64.

33. Araia MH, Potter BK. Newborn screening education on the internet: a content analysis of North American newborn screening program websites. J Community Genet 2011;2:127-34.

34. Kemper AR, Fant KE, Clark SJ. Informing parents about NBS. Public Health Nurs 2005;22:332-8.

35. Kerruish NJ, Webster D, Dickson N. Information and consent for NBS: practices and attitudes of service providers. J Med Ethics 2008;34:648-52. 


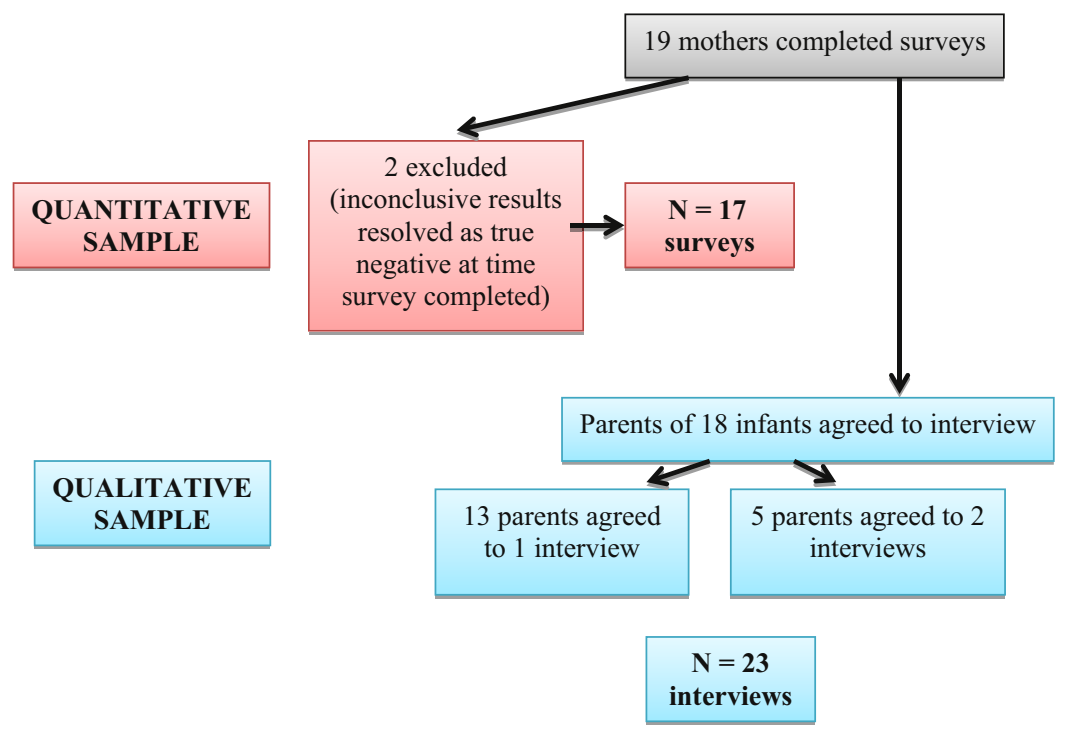

Figure. Sample of parents with infants with inconclusive results. 